\title{
Salivary Cortisol is a Good Alternative to Serum total Cortisol in Intensive Care Unit of Imam Reza Hospital of Mashhad, Iran
}

\author{
Zohreh Mousavi ${ }^{1}$, Masoud Mohebbi ${ }^{1 *}$, Shohreh Vojouhi ${ }^{1}$, Moein Mohebbi ${ }^{2}$, Amir R. Afshari ${ }^{3}$, Mohammad Mahdi \\ Vahedi ${ }^{3}$ and nazanin nikdoust ${ }^{4}$
}

${ }^{1}$ Metabolic Syndrome Research Center, Mashhad University of Medical Sciences, Iran

${ }^{2}$ Department of infectious Diseases, Mashhad University of Medical Sciences, Iran

${ }^{3}$ Department of Pharmacology, Mashhad University of Medical Sciences, Iran

${ }^{4}$ Department of Internal Medicine, Mashhad University of Medical Sciences, Iran

Submission: April 15, 2019; Published: May 06, 2019

*Corresponding author: Masoud Mohebbi, Metabolic Syndrome Research Center, Mashhad University of Medical Sciences, Mashhad, Iran

\section{Abstract}

Background: Free cortisol level increases during severe diseases, and it is suggested that there is a relation between the serum free cortisol level and the severity of illness. But in critically ill patients, a period of adrenal insufficiency may occur. Serum, saliva, urine or other body fluids may be used to measure free cortisol level. In this study, we have evaluated the relation between Serum free cortisol level and saliva, or urine cortisol compared for patients' prognosis according to APACHE III score.

Method and Materials: Thirty critically ill patients with APACHE III score of higher than 15 were enrolled in this study in internal intensive care unit. Serum, saliva and urine samples were taken in the first and seventh day of admission in ICU and free cortisol level was evaluated in each sample. APACHE III score was also calculated for all cases.

Results: Male to female ratio was 19: 11 in our series, and mean age was 57.4 \pm 11.54 years. Mean APACHE III score in the first and seventh day of admission in ICU were 39.16 \pm 12.44 and $28.16 \pm 17.89$, respectively. In comparison of serum free cortisol and salivary and urine cortisol among our patients with favorable or poor prognosis according to APACHE III score, there was a significant difference between favorable and poor prognosis groups in free serum and salivary cortisol. There was also a linear correlation between free serum cortisol and salivary cortisol in the first day of admission.

Conclusion: Partial corticosteroid increase often occurs in severe diseases, but a period of adrenal insufficiency may occur in critically ill patients that is related with poor prognosis of patients. Salivary cortisol may reflect serum free cortisol especially in early phase of ICU admission.

Keywords: Critically ill patient; Adrenal; Cortisol; Serum; Saliva; Urine

\section{Introduction}

All physiologic functions have an endogenous rhythm, which is modulated by neuroendocrine signals and is regulated by the circadian clock. The rhythms are entrained to their natural environment by light, feeding, and other social cues with light being the most critical factor. The central clock resides in the suprachiasmatic nucleus (SCN) within the hypothalamus and serves as the master pacemaker for the individual [1]. The SCN not only determines the timing of sleep and wakefulness but additionally directs other circadian rhythms especially cortisol levels, melatonin release, and core body temperature (CBT). The measurement of cortisol has emerged as a first-line test in the evaluation of the hypothalamic- pituitary-adrenal (HPA) axis in humans. Corticosteroid-binding globulin (CBG) monitors supplies of glucocorticoids by constraining the amount of unbound steroid in the blood. In any case, no less than $90 \%$ of the cortisol in human plasma is bound to CBG, and the possibility that CBG may assume a more straightforward part in steroid delivery to target cells has been considered [2,3].

Important component of the acute inflammatory response, trauma, disease and infection is an increase in corticosteroid levels especially cortisol. Systemically, the pro-inflammatory cytokines interleukin-1b (IL-1 $\beta$ ) and tumor necrosis factor 
a (TNF- $\alpha$ ) produced as part of the acute phase response to inflammation cause activation of the HPA axis and increased circulating level of cortisol. During the severe diseases and cytokine-mediated, the HPA is stimulated and the negative regulation has been removed from the axis consequently, nonbinding globulin levels will increase [4]. Over $90 \%$ of the cortisol in the circulation is bound to proteins (85\% to trans-cortine and $10 \%$ to albumin) and the biological activity depends exclusively on the free fraction. Since free cortisol has urinary excretion, the measurement of 24 hours' urine is a convenient way to check the free cortisol.

Hence, this method due to disruptions in renal output and urine collection is not very accurate [5]. Salivary cortisol measurements display various circumstances to conquer these technical problems as cortisol in saliva is available just in the biologically form. Notwithstanding, salivary cortisol display in more advantages than serum cortisol, it is not utilized as a part of clinical practice as much as serum cortisol, due to the relatively lack of publications and institutionalized cut-off focuses for the underlying screening [6]. Measuring amount of patient's illness is assessed with standard ratings as criteria APACHE (a severity of disease classification system [7]. The aim of this study is evaluation the relationship between level of cortisol in samples of body fluids with disease severity according to APACHE III model.

\section{Method}

Critically ill patients admitted to the internal ICU with a score of APACHE III $\geq 15$ who were severely without those mentioned in the (Tables $1 \& 2$ ), were enrolled. After collecting the information in the questionnaire, data were entered the SPSS 11.5 software. Then analyzing the data was carried out with Pearson test or independent t-test. The interpretation of the results by considering $\mathrm{p}<0.05$ as significant was done (Table 3 ).

Table 1: Cross-sectional study, the internal ICU patients with APACHE III $\geq 15$ were evaluated in Imam Reza Hospital

\begin{tabular}{|c|c|}
\hline Previously known HPA failure & Previously known hepatic failure \\
\hline $\begin{array}{c}\text { Glucocorticoid recipients in past year } \\
\text { (mifepristone, ketoconazole, etomidate) }\end{array}$ & Estrogen recipients in past year \\
\hline Patients with Albumin $\leq 2.5 \mathrm{mg} / \mathrm{dL}$ & $\begin{array}{c}\text { Those who have restrictions on saliva sampling such as: Dry mouth, Oral Candida or bacte- } \\
\text { rial infection, any visible bleeding of the oral cavity and the use of chlorhexidine mouth- } \\
\text { wash to prevent aspiration pneumonia caused by intubation }\end{array}$ \\
\hline Pregnancy & \begin{tabular}{c} 
Lactation \\
\hline Dialysis patients
\end{tabular} \\
\hline $\mathrm{Cr}>2 \mathrm{mg} / \mathrm{dL}$ & People aged over 70 and under 15 \\
\hline
\end{tabular}

Table 2: Scores are an expression of the degree of physiological derangement irrespective of the nature of disease

\begin{tabular}{|c|c|c|c|c|c|c|}
\hline Organ & Index & 0 & 1 & 2 & 3 & 4 \\
\hline Respiratory & $\mathrm{PaO}_{2} / \mathrm{FiO}_{2}(\mathrm{mmHg})$ & $>400$ & $\leq 400$ & $\leq 300$ & $\leq 200$ & $\leq 100$ \\
\hline Coagulation & Platelets $\times 10^{3} / \mu \mathrm{l}$ & $>150$ & $\leq 150$ & $\leq 100$ & $\leq 50$ & $\leq 20$ \\
\hline Liver & Bilirubin $(\mathrm{mg} / \mathrm{dl})[\mu \mathrm{mol} / \mathrm{L}]$ & $<1.2$ & $1.2-1.9$ & $2-5.9$ & $6-11.9$ & $>12$ \\
\hline Cardiovascular & $\begin{array}{c}\text { MAP OR administration of } \\
\text { vasopressors }\end{array}$ & $(+)$ & $\mathrm{MAP}<70 \mathrm{~mm} / \mathrm{Hg}$ & $\mathrm{dop}<5$ & $\mathrm{dop} \geq 5$ & $\mathrm{dop}>15$ \\
\hline Kidneys & $\begin{array}{c}\text { Creatinine (mg/dl) (urine } \\
\text { output) }\end{array}$ & $<1.2$ & $1.2-1.9$ & $2-3.4$ & $3.5-4.9(<500 \mathrm{ml} / \mathrm{d})$ & $\geq 5(<200 \mathrm{ml} / \mathrm{d})$ \\
\hline CNS & GCS & 15 & $13-14$ & $10-12$ & $6-9$ & $3-6$ \\
\hline
\end{tabular}

Table 3: Interpretation of the results by considering $p<0.05$ as significant

\begin{tabular}{|c|c|c|c|c|}
\hline Variant & Type & Scale & Description & Module \\
\hline Total serum cortisol & Quantitive & Rational & Bind to plasma proteins and free serum cortisol & $\mu \mathrm{g} / \mathrm{dL}$ \\
\hline Salivary free cortisol & Quantitive & Rational & Free cortisol secreted in saliva & $\mathrm{nmol} / \mathrm{L}$ or ng/cc \\
\hline Urine free cortisol & Quantitve & Rational & Free cortisol and its metabolits in urine & $\mu \mathrm{g} / \mathrm{day}$ or nmol/day \\
\hline APACHE-III scoring system & Quantitve & Spatial & Scoring system based on several indexes & Numberic \\
\hline Prognosis & Qualitive & Verbal & $\begin{array}{c}\text { Death, getting out of ICU with APACHE-III } \leq 10, \text { APACHE-III } \leq 10 \\
\text { even if he is in ICU }\end{array}$ & \\
\hline
\end{tabular}

\section{Results}

Evaluation of sex frequency distribution showed that 11 (36.7\%) and 19 (63.3\%) were females and males, respectively
(Figure 1). Evaluation of patients in ICU demonstrated that the average age was $57.4 \pm 11.54$ (Figure 2). Evaluation of ICU inpatients exhibited that average of APACHE III score was 39.16 \pm 12.44 at first day of hospitalization (Figure 3). Assessment 


\section{Journal of Endocrinology and Thyroid Research}

of serum, urine and saliva cortisol levels on the first day of inpatients, were as follows (Table 4). Evaluation of ICU inpatients exhibited that average of APACHE III score was $28.16 \pm 17.89 \mathrm{after}$ 1 week of hospitalization (Figure 4). Assessment of serum, urine and saliva cortisol levels after 1 week of hospitalization, were as follows (Tables 5-8). According to APACHE III score changes in ICU inpatients, they were divided into 2 groups with ascending score that shows deteriorating patient and descending score that shows recovering patients. 7 (23.3\%) patients in deteriorating group and $23(76.7 \%)$ patients in recovering group were placed (Figure 5) (Table 9).

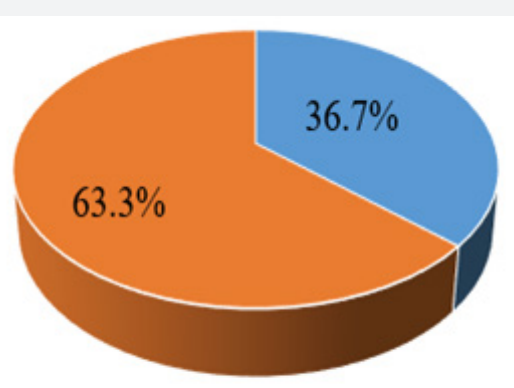

" Female "Male

Figure 1: Sex frequency distribution in critical patients in ICU.

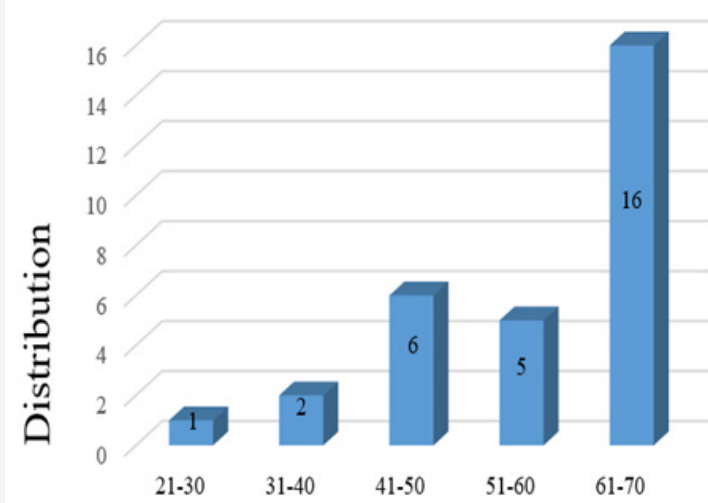

Figure 2: Age frequency distribution of ICU inpatients.

Table 4: First day of hospitalization.

\begin{tabular}{|c|c|c|c|c|}
\hline $\begin{array}{c}\text { Cortisol } \\
\text { level }\end{array}$ & Average & $\begin{array}{c}\text { Standard } \\
\text { deviation }\end{array}$ & Minimum & Maximum \\
\hline Serum & 22.9 & 11.93 & 8 & 55 \\
\hline Urine & 131.4 & 43.04 & 20 & 230 \\
\hline Saliva & 7.6 & 7.11 & 0.4 & 32.5 \\
\hline
\end{tabular}

Table 5: After 7 days of hospitalization.

\begin{tabular}{|c|c|c|c|c|}
\hline $\begin{array}{c}\text { Cortisol } \\
\text { level }\end{array}$ & Average & $\begin{array}{c}\text { Standard } \\
\text { deviation }\end{array}$ & Minimum & Maximum \\
\hline Serum & 16.5 & 6.3 & 5 & 21 \\
\hline Urine & 78.5 & 36.96 & 39 & 192 \\
\hline Saliva & 1.7 & 1.04 & 0.2 & 3.3 \\
\hline
\end{tabular}

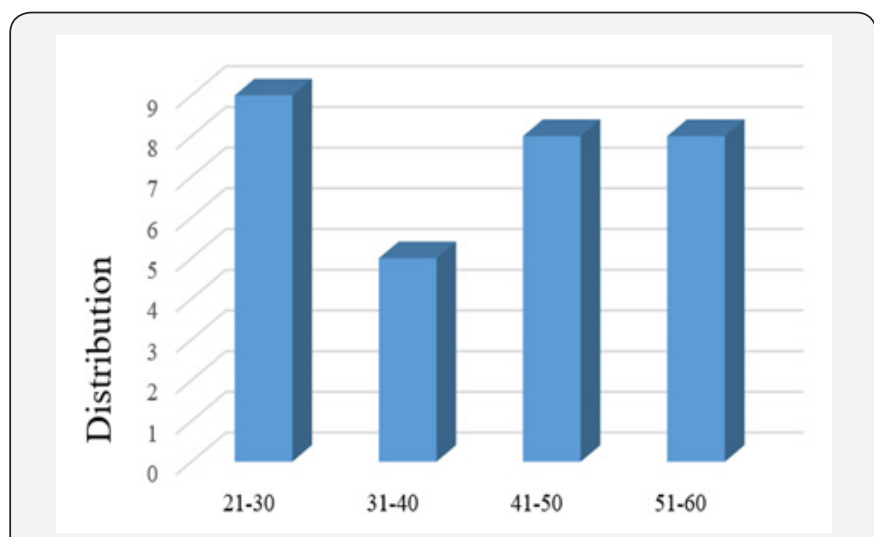

Figure 3: Frequency distribution of ICU inpatients according to APACHE III score at first day of hospitalization.

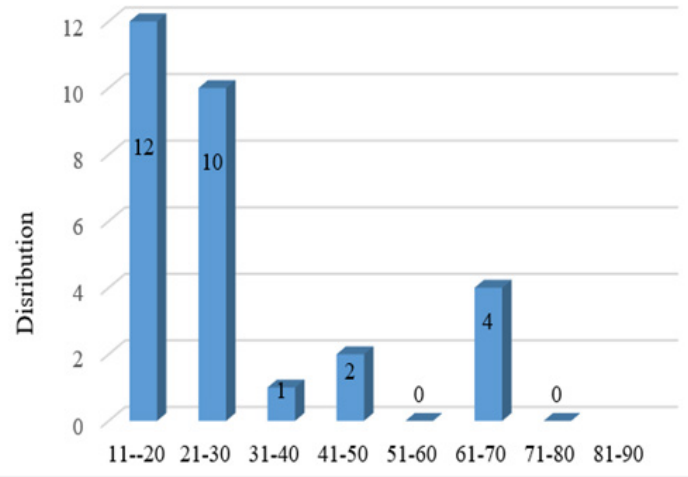

Figure 4: Frequency distribution of ICU inpatients according to APACHE III score after 1 week of hospitalization.

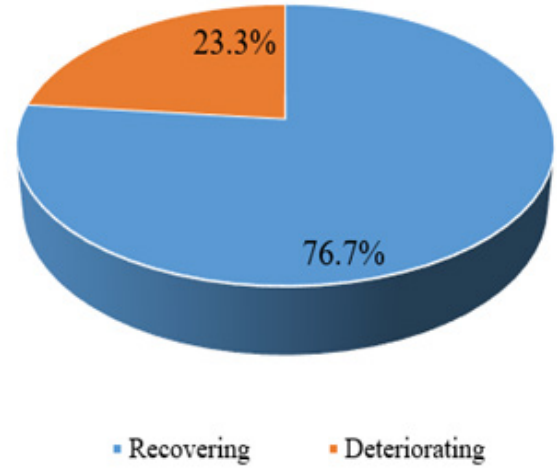

Figure 5: Frequency distribution of ICU inpatients according to APACHE III score.

Table 6: Compare of serum total cortisol level, urine and saliva cortisol levels in patients hospitalized in ICU, Divided prognosis of patients at first day.

\begin{tabular}{|c|c|c|c|}
\hline $\begin{array}{c}\text { Cortisol level } \\
\text { at first day }\end{array}$ & $\begin{array}{c}\text { Favorable } \\
\text { prognosis }\end{array}$ & $\begin{array}{c}\text { Unfavorable } \\
\text { prognosis }\end{array}$ & P-value \\
\hline Serum & $29.7 \pm 10.88$ & $12.9 \pm 2.67$ & 0.0001 \\
\hline Urine & $142.3 \pm 43.7$ & $115.1 \pm 37.9$ & 0.053 \\
\hline Saliva & $10.2 \pm 7.44$ & $3.8 \pm 4.57$ & 0.002 \\
\hline
\end{tabular}




\section{Journal of Endocrinology and Thyroid Research}

Table 7: Compare of serum total cortisol level, urine and saliva cortisol levels in patients hospitalized in ICU, Divided prognosis of patients after 1 week.

\begin{tabular}{|c|c|c|c|}
\hline Cortisol level at first day & Favorable prognosis & Unfavorable prognosis & P-value \\
\hline Serum & $20.5 \pm 6.61$ & $13.28 \pm 6.42$ & 0.023 \\
\hline Urine & $80.1 \pm 39.44$ & $73.0 \pm 29.21$ & 0.825 \\
\hline Saliva & $2.17 \pm 0.86$ & $0.5 \pm 0.23$ & 0.001 \\
\hline
\end{tabular}

Table 8: Pearson test linear relationship results between serum total cortisol, and saliva and urine total cortisol

\begin{tabular}{|c|c|c|c|c|}
\hline Compare association & $\begin{array}{c}\text { The initial serum total } \\
\text { cortisol and initial saliva } \\
\text { cortisol }\end{array}$ & $\begin{array}{c}\text { The day 7 serum cortisol } \\
\text { and day 7 saliva cortisol }\end{array}$ & $\begin{array}{c}\text { The initial serum cortisol } \\
\text { and initial urine cortisol }\end{array}$ & $\begin{array}{c}\text { The day 7 serum cortisol } \\
\text { and day 7 urine cortisol }\end{array}$ \\
\hline P-value & 0.012 & 0.124 & 0.166 & 0.651 \\
\hline R & 0.451 & 0.124 & 0.26 & 0.651 \\
\hline
\end{tabular}

Table 9: Compare of serum, urine and saliva cortisol levels at first day in ICU inpatients according to APACHE III score.

\begin{tabular}{|c|c|c|c|}
\hline Cortisol level at first day & Recovering process & Deteriorating process & p-value \\
\hline Serum & $21.8 \pm 11.65$ & $26.7 \pm 12.99$ & 0.386 \\
\hline Urine & $126.0 \pm 45.87$ & $149.4 \pm 27.39$ & 0.174 \\
\hline Saliva & $7.1 \pm 7.08$ & $9.4 \pm 7.48$ & 0.501 \\
\hline
\end{tabular}

Assessment of serum, urine and saliva cortisol levels at first day according to APACHE III score, there were not significant differences in two groups, according to Man-Whitney test. However, in deteriorating group the average of cortisol level was higher in each 3 samples. Assessment of serum, urine and saliva cortisol levels in deteriorating and recovering groups, were as follows 1 week of hospitalization (Table 10). Assessment of serum, urine and saliva cortisol levels in deteriorating and recovering groups, after 1 week of hospitalization. There was a significant difference in salivary cortisol levels in two groups however, there were not significant differences in serum and urine cortisol levels. Compare of cortisol changes in ICU inpatients were as follows in recovering and deteriorating groups (Table 11).

Table 10: Compare of cortisol changes in ICU inpatients according to APACHE III score.

\begin{tabular}{|c|c|c|c|}
\hline Cortisol level at first day & Recovering process & Deteriorating process & p-value \\
\hline Serum & $20.1 \pm 6.57$ & $14.7 \pm 8.05$ & 0.086 \\
\hline Urine & $81.6 \pm 39.19$ & $68.3 \pm 28.47$ & 0.441 \\
\hline Saliva & $2.1 \pm 0.90$ & $0.97 \pm 0.84$ & 0.003 \\
\hline
\end{tabular}

Table 11: Compare of cortisol changes in ICU inpatients according to APACHE III score.

\begin{tabular}{|c|c|c|c|c|}
\hline \multirow{2}{*}{ Cortisol changes } & \multicolumn{2}{|c|}{ Recovering process } & \multicolumn{2}{c|}{ Deteriorating process } \\
\cline { 2 - 5 } & Frequency & Percent & Frequency & 71.4 \\
\hline Decreasing & 12 & 52.2 & 5 & 28.6 \\
\hline Increasing & 11 & 47.8 & 2 & 100 \\
\hline Sum & 23 & 100 & 7 & \\
\hline
\end{tabular}

Compare of cortisol changes regarding to Chi-square test, there was not significant differences in two groups $(\mathrm{P}=0.368)$. Although it was expected that deteriorating group shows an increasing cortisol levels, but it has been shown that there were not ascending cortisol levels in many of these patients. So, it is concluded that these patients had a partial adrenal failure. In deteriorating patients, despite an increasing in APACHE III score, cortisol levels on the seventh day compared to the first day decreased (serum, urine and salivary). Average of APACHE III scores were 33.6, 48 on fist and seventh day, respectively. Average of cortisol levels were 30 and 12.5 on first and seventh day, respectively.

\section{Discussion}

Activation of the HPA axis represents one of several important body respond to stressful events such as severe illness [8]. It has been shown that in the patients with normal adrenal activity, glucocorticoid secretion particularly cortisol increases during severe illness, and it has important role in the physiological function during stressors and critical illness [9]. It can be concluded that the degree of axis activation depends on the degree of stressor. Although, the increase in serum cortisol concentration may not be linear correlation with disease severity, but studies have shown that patients with the highest levels of cortisol, have the highest mortality rate [10]. 
Since, over $90 \%$ of the cortisol in the circulation is bound to proteins so, increasing level of hypo-proteinemia commonly seen in critically ill patients, may not have been recognized [11]. General agreement is that the serum free cortisol bound to a protein, is more responsible for physiologic functions hormones. However, the standard determination of adrenal insufficiency is cosyntropin test and it is still useful, despite known limitations. But usually due to this difficulty, measuring serum free cortisol for this purpose is used $[12,13]$. The advantage of measuring serum free cortisol to total cortisol for assessment of the function of the adrenal has been proven during severe illnesses. However, although the serum free cortisol level measurement can be done, but normally it cannot be used [14].

So, we must look for alternative ways to determine the possible failure of the adrenal during a critical illness and start and decision for glucocorticoid treatment. We also need to look for relations between the critically illness of patients with serum cortisol levels (according to the presence or absence of Hypoproteinemia) according to the APACHE score and prognosis due to adrenal strength in cortisol levels increasing in the body. Recent studies have shown that salivary free cortisol levels is in balance and it is dependent on the free serum levels [15]. In a study, it has been shown the relation between stress and serum cortisol with regards to serum albumin level however none of them are not still at the level of practical and clinical utility and treatment decisions [8]. In addition, no study been carried out about the relationship between serum total cortisol and urinary free cortisol to determine serum free cortisol and its relationship with APACHE III score.

In this study, we evaluated the APACHE III criteria and levels of cortisol serum, saliva and urine cortisol in the first and seventh days of stay there on thirty critically ill patients admitted to ICU. The ratio of men to women 19 to 11 and the mean age was $57.4 \pm 11.54$ years. APACHE III average score of $39.16 \pm 12.44$ on the first day and on the seventh day was $28.16 \pm 17.89$. Serum total cortisol in urine and saliva cortisol levels in patients with favorable and unfavorable prognosis significant difference in the level of serum total cortisol and salivary based on APACHE score in the two groups. In examining the relationship between serum total cortisol levels cortisol in saliva and urine, a significant linear correlation found between cortisol levels in the serum and saliva on the first day.

According to changes in the criteria for critically ill patients in ICU, the patients were divided to groups that first group expresses the course of deteriorating patients with increasing APACHE score and those with lower APACHE scores that expresses the course of the recovery. Comparing levels of serum, urine and saliva cortisol, the patients with APACHE III score changes, it was not significant difference in both groups on the first day according to Mann-Whitney test results. Although in deteriorated group the mean of serum cortisol level in all three samples were higher. This significant difference can be explained as follows that because we have formed two groups to be retrograde, people with high and low APACHE scores were placed in these groups and correspondingly high and low cortisol levels were divided in two groups so, the difference was not significant.

The group continues to improve, as expected, $52 \%$ were declining cortisol but, in $48 \%$ of cases, cortisol levels were rising. It can suggest is that in a person with normal functioning adrenal, cortisol can stabilize the patient's condition and help patient recovery. On the other hand, in deteriorating group, although it was expected that increased cortisol but, it was observed that only in $29 \%$ cortisol increased. In $71 \%$ of patients, despite an increase in APACHE, cortisol was declining that they may have adrenal insufficiency. So, it was found that patients often along with the progression of the disease cortisol level has changed and cortisol increases with the exacerbation of patient. But, the situation is changed in critically ill patients and they have some degree of adrenal insufficiency that caused poor prognosis in patients.

In review of a study, in 2008 in China, adrenal insufficiency was investigated in severe chronic diseases and they found that patients with less than 15 cortisol level had longer hospitalization and their clinical prognosis was even worse [16]. In another study in 2007 by Arafah et al., a close connection between salivary cortisol and serum free cortisol was found [17]. Furthermore, in a study, critically ill patients showed a greater degree of adrenal insufficiency [18]. In a study was conducted by Walker in 2011 in Atlanta, the incidence of sepsis, bacteremia, and pneumonia was higher in patients with adrenal insufficiency, and the findings showed that the incidence of adrenal insufficiency in critically ill traumatic patients is associated with increased mortality, even if the treatment of patients with steroid also be done [19]. In another study, the incidence of adrenal insufficiency in critically ill patients were studied. This is a controversial issue in different studies. It was shown that in critically ill patients, with onset of the stress steroid levels rises, but with the advancement of the inflammatory phase, the HPA axis disrupts and adrenal insufficiency occurs [20].

\section{Conclusion}

In critically ill patients, partial increase is found in cortisol levels, but it is probable that incidence of adrenal insufficiency in critically ill patients is related with the worst prognosis. With further investigation, the probability of this failure can be associated with APACHE (a score which indicates the severity of disease) to predict the adrenal failure and consequently begin the steroid therapy as soon as possible for the patient. Now, most measures of cortisol are based on the serum total cortisol, which is influenced the changes in serum protein and therefore the exact amount of free cortisol, especially in severely ill patients is not feasible. In this study, salivary cortisol reflects well serum total cortisol, especially in the early days. Given that in this study 
we have excluded hypo-albuminemic patients of the project so, these results can also be suggestive of serum free cortisol and salivary cortisol relationship because salivary cortisol is easy to measurement, non-invasive and is also cost-effective so, it can be a good alternative to serum free cortisol. Because according to the limitations in this study we did not to evaluate serum free cortisol, it is suggested, a study to be done with a wider range and serum total, free and salivary cortisol measurements to achieve more definitive results.

\section{References}

1. Billings ME, Watson NF (2015) Circadian dysrhythmias in the intensive care unit. Critical care clinics 31(3): 393-402.

2. Kalsbeek A, Van der Spek R, Lei J, Endert E, Buijs R, et al. (2012) Circadian rhythms in the hypothalamo-pituitary-adrenal (HPA) axis. Molecular and cellular endocrinology 349(1): 20-29.

3. Wright KP, Drake AL, Frey DJ, Fleshner M, Desouza CA, et al. (2015) Influence of sleep deprivation and circadian misalignment on cortisol, inflammatory markers, and cytokine balance. Brain, behavior, and immunity 47: 24-34.

4. Peeters B, Boonen E, Langouche L, Van den Berghe G (2015) The HPA axis response to critical illness: New study results with diagnostic and therapeutic implications. Molecular and cellular endocrinology 408: 235-240.

5. Restituto P, Galofré J, Gil M, Mugueta C, Santos S, et al. (2008) Advantage of salivary cortisol measurements in the diagnosis of glucocorticoid related disorders. Clinical biochemistry 41(9): 688-692.

6. Patel RS, Shaw SR, MacIntyre H, McGarry GW, Michael Wallace A (2004) Production of gender-specific morning salivary cortisol reference intervals using internationally accepted procedures. Clinical Chemical Laboratory Medicine 42(12): 1424-1429.

7. Knaus WA, Draper EA, Wagner DP, Zimmerman JE (1985) APACHE II: a severity of disease classification system. Critical care medicine 13(10): 818-829.

8. Arafah BM (2006) Hypothalamic pituitary adrenal function during critical illness: limitations of current assessment methods. The Journal of Clinical Endocrinology \& Metabolism 91(10): 3725-3745.
9. Ho J, Al-Musalhi H, Chapman M, Quach T, Thomas P, et al. (2006) Septic shock and sepsis: a comparison of total and free plasma cortisol levels. The Journal of Clinical Endocrinology \& Metabolism 91(1): 105-114.

10. Sam S, Corbridge TC, Mokhlesi B, Comellas AP, Molitch ME (2004) Cortisol levels and mortality in severe sepsis. Clinical endocrinology 60(1): 29-35.

11. Hamrahian AH, Oseni TS, Arafah BM (2004) Measurements of serum free cortisol in critically ill patients. New England Journal of Medicine 350(16): 1629-1638.

12. Hammond Gl (1990) Molecular Properties of Corticosteroid Binding Globulin And The Sex-Steroid Binding Proteins*. Endocrine Reviews 11(1): 65-79.

13. Cooper MS, Stewart PM (2003) Corticosteroid insufficiency in acutely ill patients. New England Journal of Medicine 348(8): 727-734.

14. Nasrallah MP, Arafah BM (2003) The value of dehydroepiandrosterone sulfate measurements in the assessment of adrenal function. The Journal of Clinical Endocrinology \& Metabolism 88(11): 5293-5298.

15. Streeten D, Anderson Jr G, Bonaventura MM (1996) The potential for serious consequences from misinterpreting normal responses to the rapid adrenocorticotropin test. The Journal of Clinical Endocrinology \& Metabolism 81(1): 285-290.

16. Wu JY, Hsu SC, Ku SC, Ho CC, Yu CJ, et al. (2008) Adrenal insufficiency in prolonged critical illness. Critical Care 12(3): R65.

17. Arafah BM, Nishiyama FJ, Tlaygeh H, Hejal R (2007) Measurement of salivary cortisol concentration in the assessment of adrenal function in critically ill subjects: a surrogate marker of the circulating free cortisol. The Journal of Clinical Endocrinology \& Metabolism 92 (8): 2965-2971.

18. Annane D, Maxime V, Ibrahim F, Alvarez JC, Abe E, et al. (2006) Diagnosis of adrenal insufficiency in severe sepsis and septic shock. American journal of respiratory and critical care medicine 174(12): 1319-1326.

19. Walker ML, Owen PS, Sampson C, Marshall J, Pounds T, et al. (2011) Incidence and outcomes of critical illness-related corticosteroid insufficiency in trauma patients. The American Surgeon 77(5): 579585.

20. Marik PE (2009) Critical illness-related corticosteroid insufficiency. Chest Journal 135(1): 181-193.

\begin{tabular}{l} 
Your next submission with Juniper Publishers \\
will reach you the below assets \\
- Quality Editorial service \\
- Swift Peer Review \\
- Reprints availability \\
- E-prints Service \\
- Manuscript Podcast for convenient understanding \\
- Global attainment for your research \\
- Manuscript accessibility in different formats \\
( Pdf, E-pub, Full Text, Audio) \\
- Unceasing customer service \\
Track the below URL for one-step submission \\
https://juniperpublishers.com/online-submission.php \\
\hline
\end{tabular}

